\title{
BMJ Open Safety culture in a pharmacy setting using a pharmacy survey on patient safety culture: a cross-sectional study in China
}

\author{
P L Jia, ${ }^{1}$ L H Zhang, ${ }^{1}$ M M Zhang, ${ }^{1} \mathrm{~L} L$ Zhang, ${ }^{2} \mathrm{C}$ Zhang, ${ }^{2} \mathrm{~S} F \mathrm{Qin},{ }^{3} \mathrm{X} \mathrm{L} \mathrm{Li,}{ }^{4}$ \\ KX Liu ${ }^{5}$
}

To cite: Jia PL, Zhang LH, Zhang MM, et al. Safety culture in a pharmacy setting using a pharmacy survey on patient safety culture: a cross-sectional study in China. BMJ Open 2014;4: e004904. doi:10.1136/ bmjopen-2014-004904

- Prepublication history and additional material is available. To view please visit the journal (http://dx.doi.org/ 10.1136/bmjopen-2014004904)

PLJ and LHZ contributed equally

Received 21 January 2014 Revised 22 May 2014 Accepted 6 June 2014

CrossMark

For numbered affiliations see end of article.

Correspondence to Professor MM Zhang; mingming-zhang@163.com

\section{ABSTRACT}

Objective: To explore the attitudes and perceptions of patient safety culture for pharmacy workers in China by using a Pharmacy Survey on Patient Safety Culture (PSOPSC), and to assess the psychometric properties of the translated Chinese language version of the PSOPSC.

Design: Cross-sectional study.

Participants: Data were obtained from 20 hospital pharmacies in the southwest part of China.

Methods: We performed $\chi^{2}$ test to explore the differences on pharmacy staff in different hospital and qualification levels and countries towards patient safety culture. We also computed descriptive statistics, internal consistency coefficients and intersubscale correlation analysis, and then conducted an exploratory factor analysis. A test-retest was performed to assess reproducibility of the items.

Results: A total of 630 questionnaires were distributed of which 527 were responded to validly (response rate $84 \%)$. The positive response rate for each item ranged from $37 \%$ to $90 \%$. The positive response rate on three dimensions ('Teamwork', 'Staff Training and Skills' and 'Staffing, Work Pressure and Pace') was higher than that of Agency for Healthcare Research and Quality (AHRQ) data $(p<0.05)$. There was a statistical difference in the perception of patient safety culture at different hospital and qualification levels. The internal consistency of the total survey was comparatively satisfied (Cronbach's $\alpha=0.89$ ).

Conclusions: The results demonstrated that among the pharmacy staffs surveyed in China, there was a positive attitude towards patient safety culture in their organisations. Identifying perspectives of patient safety culture from pharmacists in different hospital and qualification levels are important, since this can help support decisions about action to improve safety culture in pharmacy settings. The Chinese translation of the PSOPSC questionnaire (V.2012) applied in our study is acceptable.

\section{BACKGROUND}

Medication errors are the largest component of medical errors accounting for about a quarter of the incidents which threaten patient safety. ${ }^{1}$ An estimated 770000 people

\section{Strengths and limitations of this study}

- This is the first kind of study that was conducted in China measuring patient safety culture in a pharmacy setting. The results of this study may provide some evidence to help healthcare decision makers or policymakers in pharmacy settings from developing countries to develop effective strategies to assess areas of strength and identify areas for improvement in their patient safety culture as part of their quality improvement activities.

- Findings might be limited by selection bias as pharmacies were selected on a convenience basis. Our study was carried out only in the second-grade and third-grade hospitals, which may not reflect the whole picture of patient safety culture in China. Meanwhile, this is the first kind of study using the Pharmacy Survey on Patient Safety Culture (PSOPSC) to measure safety culture in a pharmacy setting; there are no similar studies from benchmark scores using the PSOPSC for us to compare with, so the external comparison was restrictive. Finally, because of the small sample numbers included in our study and because our primary objective is to explore the attitudes and perceptions of patient safety culture for pharmacy workers, we did not conduct confirmatory factor analysis to test hypotheses about a particular factor structure.

are injured or die in hospitals from adverse drug events (ADEs) each year, which are injuries resulting from drug use. Approximately $28 \%$ of ADEs are associated with a medication error and therefore are judged to be preventable. ${ }^{2}$ Fifty per cent of these ADEs could have been prevented by a pharmacist. ${ }^{3}$ It appears that pharmacists and clinical pharmacy services can substantially improve patient safety and reduce hospital costs associated with medication errors. ${ }^{1}$ Meanwhile, a report published by the 
Institute of Medicine (IOM) indicated for a safety culture in which adverse events can be reported without people being blamed, and that when mistakes occur that lessons are learned. ${ }^{4}$ Therefore, if hospital pharmacies want to improve patient safety, it is important to know more about the views of their staff in relation to the culture of patient safety.

Today, reducing medication errors and improving patient safety have become common topics of health services around the world. ${ }^{5}$ Many developed countries have initiated research into the role played by patient safety culture research. On a global basis, several international organisations promote the establishment of a culture of patient safety: the WHO Patient Safety Programme will launch in 2014 the Third Global Patient Safety Challenge, focusing on medication safety, the National Patient Safety Agency in the UK, the Agency for Healthcare Research and Quality in the USA, the Australia Commission of Safety and Quality and the European Foundation for the Advancement of Healthcare Practitioners. ${ }^{4}{ }^{6}$ There are some developing countries that are oblivious to the problems created by medication errors. However, efforts are now being taken in these countries, especially India, China and the Philippines, to set up a pharmacovigilance system for collection of information on ADEs. ${ }^{6-8}$

As pharmacies continually strive to improve safety and quality, there is a growing recognition of the importance of establishing a culture of patient safety. Achieving such a culture requires an understanding of the values and beliefs about what is important in the organisation and what attitudes and behaviours related to patient safety are expected. ${ }^{9}$ The assessment of safety culture in pharmacies has recently begun to develop and the consistency of methods and instruments used across pharmacies needs to be further elaborated. ${ }^{10}$ Quite often, hospital pharmacies have been included in the overall hospital-based safety culture assessments. ${ }^{11-16}$ There are a few studies of pharmacy survey on patient safety culture by using different scales. ${ }^{10}{ }^{17-19}$ However, most of these studies focused on the evaluation of the psychometric properties of the scales or on developing and examining the component structure and internal consistency of the survey instruments. ${ }^{10} 18{ }^{19}$ For example, the study by Ashcroft and Parker $^{19}$ aims to develop a Pharmacy Safety Climate Questionnaire (PSCQ) and examine the component structure and internal consistency in the community pharmacy setting in England. Nevertheless, no study until now, to the best of our knowledge, using a survey developed for pharmacists has been published in which the safety culture in hospital pharmacies has been assessed.

In this study, the patient safety culture in China's hospital pharmacies was measured by using the modified version of the PSOPSC developed by AHRQ (V.2012). ${ }^{9}$ We also compared some of the findings with existing data from the AHRQ pilot study. Meanwhile, we intended to assess the quality of this investigative questionnaire.

\section{METHODS}

\section{Questionnaire}

The PSOPSC was translated and modified to suit the Chinese system. The original PSOPSC was developed by AHRQ in 2012 on the basis of a pilot study which was designed to assess 11 dimensions of pharmacy with 36 items of patient safety culture. ${ }^{9}$ The questionnaire also included three questions that ask respondents to rate the frequency with which mistakes were documented and one question that provides an overall rating on patient safety. ${ }^{20}$ Additionally, the original PSOPSC contained a section of 'Background Questions' as well as an open-ended section. We made a slight emendation of the PSOPSC questionnaire by combining two items (A3: "Technicians in this pharmacy receive the training they need to do their jobs" and A10: "Staff get enough training from this pharmacy") into one item because they had almost the same meaning in the Chinese translation. Furthermore, we added two items to the section 'Background Questions' (gender and hospital levels) and refreshed the qualification categories to adapt to the Chinese context (see online supplementary table).

The survey used either five-point agreement scales ('Strongly disagree' to 'Strongly agree') or frequency scales ('Never' to 'Always'). Items include a 'Does not apply or Don't know' option. ${ }^{20}$

The permission to use and translate the PSOPSC was obtained from AHRQ. We did not use 'translation-back translation techniques', because we were informed by our language experts that 'translation-back translation techniques' were a good approach for some languages, especially for the Latin language system; however, it may not be one of the best approaches for the Chinese translation, which has a totally different language system. The Chinese translation was carried out in several steps. First, the recommended guideline of the PSOPSC: User's Guide was carefully discussed within the research group before translation. The first translation was performed by a graduate medical student with a background in patient safety. Then the translation was double checked and reviewed by the research group including experts in pharmacy, methodologists and English. Finally, we pretested the translation in the pilot investigation among 30 pharmacy staff for further improvement before formal investigation. We had a further discussion regarding some wordings and especially on some items that would cause a misunderstanding in the Chinese language (eg, the items of "We feel rushed when processing prescriptions", Staff feel like their mistakes are held against them", "Staff feel comfortable asking questions when they are unsure about something" and the last section of 'Documenting Mistakes').

\section{Sample}

Convenience sampling was used to survey hospital pharmacies (one of the hospital departments) throughout the southwest part of China. The self-administered questionnaire was conducted over 6 months from March to 
August 2013 with 20 hospital pharmacies included (pharmacy workers ranging from 30 to 60 in each hospital). We involved all pharmacy staff working in the pharmacy area where prescriptions were dropped off, filled, dispensed and picked up or prepared for delivery. ${ }^{9}$

The pharmacy staff included senior pharmacists (at least 3 years university education and working time must more than 9 years in the pharmacy), junior pharmacists (at least 3 years university education and working time is less than 9 years in the pharmacy) and a pharmacy intern who was still an undergraduate and just worked in a pharmacy in his spare time.

To ensure the privacy of the respondents, the survey was strictly anonymous. Permission to conduct the investigation was granted by the hospital pharmacy directors before investigation. The participants were informed of the purpose of the survey and voluntarily completed a paper copy of the questionnaire by the research coordinators in different hospitals.

\section{Data screening and collection}

After receiving the completed questionnaires, a preprocessing step was applied to remove incomplete or invalid data and based on the study by Hellings et $a l^{14}$ we checked and examined the returned questionnaire. The exclusion criteria were similar to the other two studies: (1) there was no entire section completed; (2) there were fewer than half items answered or all the items answered the same. ${ }^{4}{ }^{14}$ All data were entered by two researchers (PLJ and LHZ) independently, and they were cross-checked mutually by Epidata (V.3.02). In case of doubts or disagreement in some answers, we looked into the original questionnaires. Negatively worded items were reversed to ensure that positive answers indicated a higher score. Most of the items in the questionnaire used the Likert five-point response scale of agreement (Strongly disagree to Strongly agree) or frequency (Never to Always), so the lowest three scoring (1-3) answers (Strongly disagree/Disagree/Neither Agree nor Disagree or Never/Rarely/Sometimes), the highest two scoring (4-5) answers (Agree/Strongly agree or Most of the time/Always) as well as the highest two scoring answers were perceived as positive response answers, and the lowest three scoring answers were deemed to be other response answers. We calculated the positive response rate according to the formula by the User's Guide of PSOPSC. ${ }^{9}$ Items marked as a 'Does Not Apply/Don't Know' response option by the respondents were excluded when displaying percentages of response and the positive response scores. ${ }^{9}$

\section{Data analysis}

We analysed the demographic characteristics using Excel 2007. The number of positive responses/positive response rate of all the items was also summarised. A positive response rate was used to evaluate the attitudes towards patient safety culture on different dimensions or items. We aggregated the results across all 20 pharmacies by looking at agreement indices. We used a $\chi^{2}$ test to compare whether there was a statistical difference on pharmacy staff in hospital and qualification levels towards patient safety culture. A $\chi^{2}$ test was also used to infer if there was a statistical difference in 'patient safety grade' in Chinese pharmacies compared with that in US pharmacies, with a significant level of $\mathrm{p}=0.05$.

We calculated Cronbach's $\alpha$ and exploration factor analysis to evaluate the quality of the questionnaire. Internal consistency value (Cronbach's $\alpha \geq 0.70$ ) for newly developed scales was recommended. ${ }^{4}$ Structure validity was explored using principal component factor analysis by the Kaiser-Meyer-Olkin measure of sampling adequacy $(\mathrm{KMO}>0.7)$ and by Bartlett's test of sphericity $\mathrm{p}<0.05$.

We calculated the intercorrelations among 11 dimensions using the non-parametric Spearman test as it is adapted to qualitative ordinal variables. The correlations should be less than 0.8 for the composites to be considered unique and to avoid problems with multicollinearity. ${ }^{12}$

A test-retest was administered in a specialised hospital to assess the reproducibility. Thirty-three randomly selected pharmacy staff were asked to answer the questionnaire twice with a 2-week interval between the test and the retest. Test-retest reliability was assessed by the one-way intraclass correlation coefficient (ICC type $(1,1)) .^{21}$ Reliability was considered good if ICC was greater than $0.7 .^{21}$

\section{Ethics}

This was a non-interventional survey. We were informed that it was not a mandatory requirement for ethics approval by the hospital ethics committee. However, responding to the questionnaire was voluntary and all answers were de-identified to maintain confidentiality.

\section{RESULTS}

\section{Sample and response statistics}

A total of 630 questionnaires were distributed of which 527 were responded to validly $(84 \%)$. Three hundred and seventy-nine $(72 \%)$ of the respondents were women, $421(80 \%)$ were junior pharmacists, followed by pharmacy interns (16\%) and senior pharmacists $(4 \%)$. The majority of the respondents $(68 \%)$ were from thirdgrade hospitals (table 1 ).

In our study, the percentage of positive responses for the 11 patient safety culture dimensions ranged from $50 \%$ to $88 \%$, and the mean positive response rate was $71 \%$. The lowest positive response rate of dimension was 'Staffing, Work Pressure and Pace' (50\%), while the highest positive response rate of dimension was 'Staff Training and Skills' (88\%). There were two dimensions of which positive response rate was less than $60 \%$ such as 'Patient Counseling' (57\%) and 'Staffing, Work Pressure and Pace' $(50 \%)$. The positive response rate for the rest of the items ranged from $37 \%$ to $90 \%$. The highest positive response rate of the three items reached 
Table 1 Demographic characteristics of respondents

\begin{tabular}{|c|c|c|c|c|}
\hline Characteristics & $\begin{array}{l}\text { Senior pharmacist } \\
(n=20)\end{array}$ & $\begin{array}{l}\text { Junior pharmacist } \\
(n=421)\end{array}$ & $\begin{array}{l}\text { Pharmacy intern } \\
(n=86)\end{array}$ & $\begin{array}{l}\text { Total } \\
(n=527)\end{array}$ \\
\hline \multicolumn{5}{|l|}{ Sex } \\
\hline Male & $4(2.7)$ & $115(77.7)$ & $29(19.6)$ & $148\left(100^{*}\right)$ \\
\hline Female & $16(4.2)$ & $306(80.8)$ & $57(15.0)$ & $379(100)$ \\
\hline \multicolumn{5}{|l|}{ Working time in hospital } \\
\hline Less than 6 months & $3(5.6)$ & $40(74.1)$ & $11(20.4)$ & $54(100)$ \\
\hline 6 months to less than & $5(6.4)$ & $57(73.1)$ & $16(20.5)$ & $78(100)$ \\
\hline \multicolumn{5}{|l|}{1 year } \\
\hline $1-3$ years & $5(4.0)$ & 104 (83.9) & $15(12.1)$ & $124(100)$ \\
\hline $3-6$ years & $3(3.0)$ & $82(81.2)$ & $16(15.8)$ & $101(100)$ \\
\hline $6-12$ years & $1(1.4)$ & $55(77.5)$ & $15(21.5)$ & $71(100)$ \\
\hline 12 years or more & $3(3.0)$ & $83(83.8)$ & $13(13.1)$ & $99(100)$ \\
\hline \multicolumn{5}{|c|}{ Working hours per week (hours) } \\
\hline $1-16$ & $0(0)$ & $14(87.5)$ & $2(12.5)$ & $16(100)$ \\
\hline $17-31$ & $1(4.5)$ & $18(81.8)$ & 3 (13.6) & $22(100)$ \\
\hline $32-40$ & $14(4.7)$ & 244 (73.2) & $42(14.0)$ & $300(100)$ \\
\hline More than 40 & $5(2.6)$ & $145(76.8)$ & $39(20.6)$ & $189(100)$ \\
\hline \multicolumn{5}{|l|}{ Hospital level† } \\
\hline Third-grade hospital & $14(3.9)$ & $290(81.2)$ & $53(14.8)$ & $357(100)$ \\
\hline Second-grade hospital & $6(3.5)$ & $131(77.1)$ & $33(19.4)$ & $170(100)$ \\
\hline
\end{tabular}

${ }^{*}$ Figures in parentheses represent percentage.

†Third-grade hospital: provincial and municipal hospital. Second-grade hospital: regional hospital.

$90 \%$, while the lowest positive response rate of the item was "Staff feel like their mistakes are held against them" (37\%; table 2).

However, the 2012 preliminary comparative results: PSOPSC in the USA showed that the average positive response rate of 11 dimensions ranged from $41 \%$ to $90 \%$, and the overall average positive response rate for dimensions was $78 \%$. The lowest positive response rate item was "We feel rushed when processing prescriptions" $(14 \%)$ and the highest positive response rate item was "Our pharmacists tell patients important information about their new prescriptions" (93\%). There were four items for which the positive response rate was less than $60 \%$ (table 2).

There were some differences (in the original version of the US PSOPSC, the A3: "Technicians in this pharmacy receive the training they need to do their jobs" and A10: "Staff get enough training from this pharmacy" are separate items; in our modified Chinese version, we combined the two items into a single item because they have almost the same meaning in the Chinese translation) between the adapted Chinese PSOPSC and the original US PSOPSC, so only the same items were compared to explore the differences of perceptions towards patient safety culture between the two countries. The results showed that there was a significant difference in three items $(\mathrm{p}<0.05)$, of which the positive response rate on three items in China was higher than that in the USA. These dimensions were (1) Teamwork, (2) Staffing, Work Pressure and Pace. However, there was a significant difference in 18 items $(p<0.05)$, of which the positive response rate on 18 items in China was lower than that in the USA (table 2).

\section{Comparative results}

The results showed that there was a significant difference in seven dimensions between a third-grade hospital and a second-grade hospital $(\mathrm{p}<0.05)$. The positive response rate of five items of third-grade hospitals was lower than that of second-grade hospitals: (1) This pharmacy is free of clutter, (2) Our pharmacists spend enough time talking to patients about how to use their medications; (3) Staff take adequate breaks during their shifts; (4) We feel rushed when processing prescription and (5) Interruptions/distractions in this pharmacy make it difficult for staff to work accurately $(\mathrm{p}<0.05)$. The positive response rate of other items of third-grade hospitals was higher than that of secondgrade hospitals (table 3 ).

The incidence of patient safety events was closely related to the qualification levels of pharmacists. Our results showed that there was a significant difference in the positive response rate in two dimensions ('Staffing, Work Pressure and Pace' and 'Communication About Prescriptions Across Shifts', $\mathrm{p}<0.05)$ for senior pharmacists, junior pharmacists and the pharmacy intern. Furthermore, the positive response rate of pharmacists with a high qualification (senior pharmacists) was higher than that of those with a low qualification level (junior pharmacists) on the two items: "Staff take adequate breaks during their shifts" and "We have standard procedures for communicating prescription information across shifts" $\mathrm{p}<0.05$ (table 3 ).

\section{Patient safety grade in China and the USA and different qualification levels}

The percentage of staff who rated the level of patient safety as 'Good', 'Very good' or 'Excellent' was $79 \%$ in 
Table 2 Positive response rate of each item, Cronbach's $\alpha$ for dimensions and reproducibility

\section{Dimension/items (internal consistency reliability coefficient)}

USA (\%) China (\%) ICC

1. Physical Space and Environment (Cronbach's $\alpha=0.60)$

A1. This pharmacy is well organised

A5. This pharmacy is free of clutter

72

84

A7. The physical layout of this pharmacy supports good workflow

2. Teamwork (Cronbach's $\alpha=0.44$ )

A2. Staff treat each other with respect

A4. Staff in this pharmacy clearly understand their roles and responsibilities

A9. Staff work together as an effective team

3. Staff Training and Skills (Cronbach's $\alpha=0.75$ )

A3. Technicians in this pharmacy receive the training they need to do their jobs

A6. Staff in this pharmacy have the skills they need to do their jobs well

A8. Staff who are new to this pharmacy receive adequate orientation

4. Communication Openness (Cronbach's $\alpha=0.57$ )

B1. Staff ideas and suggestions are valued in this pharmacy

B5. Staff feel comfortable asking questions when they are unsure about something

B10. It is easy for staff to speak up to their supervisor/manager about patient safety concerns in this pharmacy

5. Patient Counseling (Cronbach's $\alpha=0.69$ )

B2. We encourage patients to talk to pharmacists about their medications

B7. Our pharmacists spend enough time talking to patients about how to use their medications

B11. Our pharmacists tell patients important information about their new prescriptions

6. Staffing, Work Pressure and Pace (Cronbach's $\alpha=0.5$ )

B3. Staff take adequate breaks during their shifts

B9. We feel rushed when processing prescriptions (negatively worded)

B12. We have enough staff to handle the workload

B16. Interruptions/distractions in this pharmacy (from phone calls, faxes, customers, etc) make it difficult for staff to work accurately (negatively worded)

7. Communication About Prescriptions Across Shifts (Cronbach's $\alpha=0.84$ )

B4. We have clear expectations about exchanging important prescription information across shifts

B6. We have standard procedures for communicating prescription information across shifts

B14. The status of problematic prescriptions is well communicated across shifts

8. Communication About Mistakes (Cronbach's $\alpha=0.17$ )

B8. Staff in this pharmacy discuss mistakes

B13. When patient safety issues occur in this pharmacy, staff discuss them

B15. In this pharmacy, we talk about ways to prevent mistakes from happening again

9. Response to Mistakes (Cronbach's $\alpha=0.57$ )

C1. Staff are treated fairly when they make mistakes

C4. This pharmacy helps staff learn from their mistakes rather than punishing them

$\mathrm{C} 7$. We look at staff actions and the way we do things to understand why mistakes happen in this pharmacy

C8. Staff feel like their mistakes are held against them (negatively worded)

10. Organizational Learning-Continuous Improvement (Cronbach's $\alpha=0.48$ )

$\mathrm{C} 2$. When a mistake happens, we try to figure out what problems in the work process led to the mistake

C5. When the same mistake keeps happening, we change the way we do things

C10. Mistakes have led to positive changes in this pharmacy

11. Overall Perceptions of Patient Safety (Cronbach's $\alpha=0.45$ )

C3. This pharmacy places more emphasis on sales than on patient safety (negatively worded)

C6. This pharmacy is good at preventing mistakes

C9. The way we do things in this pharmacy reflects a strong focus on patient safety

ICC, intraclass correlation coefficient. our study, which was lower than the USA score of $95 \%$. There was a significant difference between the two groups $(\mathrm{p}<0.001)$, while there was no significant difference in 'Patient safety grade' in different qualification levels $(\mathrm{p}=0.66$; table 4$)$. Meanwhile, there was a positive correlation between 11 dimensions on the PSOPSC and overall patient safety grade. All correlations were significant at $\mathrm{p}<0.001$. The correlation coefficient ranged from 0.3 to 0.46 . In addition, there was also a positive correlation between scale and 'overall patient safety grade'. 


\begin{tabular}{|c|c|c|c|c|c|c|c|c|c|c|c|c|c|c|}
\hline \multirow[t]{3}{*}{ Items } & \multicolumn{6}{|c|}{ Hospital levels } & \multicolumn{8}{|c|}{ Qualification levels } \\
\hline & \multicolumn{2}{|c|}{$\begin{array}{l}\text { Third-grade } \\
\text { hospital }\end{array}$} & \multicolumn{2}{|c|}{$\begin{array}{l}\text { Second-grade } \\
\text { hospital }\end{array}$} & \multirow[b]{2}{*}{$\chi^{2}$} & \multirow[b]{2}{*}{ p Value } & \multicolumn{2}{|c|}{$\begin{array}{l}\text { Senior } \\
\text { pharmacist }\end{array}$} & \multicolumn{2}{|c|}{$\begin{array}{l}\text { Junior } \\
\text { pharmacist }\end{array}$} & \multicolumn{2}{|c|}{$\begin{array}{l}\text { Pharmacy } \\
\text { intern }\end{array}$} & \multirow[b]{2}{*}{$\chi^{2}$} & \multirow[b]{2}{*}{ p Value } \\
\hline & NPR & NOR & NPR & NOR & & & NPR & NOR & NPR & NOR & NPR & NOR & & \\
\hline A1. This pharmacy is well organised & 316 & 41 & 123 & 47 & 21.63 & 0.000 & 18 & 2 & 355 & 66 & 66 & 20 & 3.61 & 0.16 \\
\hline A5. This pharmacy is free of clutter & 171 & 186 & 107 & 63 & 10.45 & 0.001 & 12 & 8 & 223 & 198 & 43 & 43 & 0.69 & 0.71 \\
\hline $\begin{array}{l}\text { A7. The physical layout of this pharmacy supports good } \\
\text { workflow }\end{array}$ & 236 & 121 & 123 & 47 & 2.07 & 0.15 & 16 & 4 & 288 & 133 & 55 & 31 & 2.00 & 0.37 \\
\hline A2. Staff treat each other with respect & 308 & 49 & 141 & 29 & 1.01 & 0.31 & 18 & 2 & 360 & 61 & 71 & 15 & 0.87 & 0.65 \\
\hline $\begin{array}{l}\text { A4. Staff in this pharmacy clearly understand their roles } \\
\text { and responsibilities }\end{array}$ & 321 & 36 & 150 & 27 & 0.34 & 0.56 & 19 & 1 & 312 & 49 & 80 & 6 & 2.33 & 0.31 \\
\hline A9. Staff work together as an effective team & 283 & 74 & 116 & 54 & 7.63 & 0.006 & 16 & 4 & 321 & 100 & 62 & 24 & 0.88 & 0.65 \\
\hline $\begin{array}{l}\text { A3. Technicians in this pharmacy receive the training } \\
\text { they need to do their jobs }\end{array}$ & 308 & 49 & 139 & 31 & 1.82 & 0.18 & 14 & 6 & 353 & 68 & 73 & 13 & 2.80 & 0.25 \\
\hline $\begin{array}{l}\text { A6. Staff in this pharmacy have the skills they need to do } \\
\text { their jobs well }\end{array}$ & 319 & 38 & 150 & 27 & 0.15 & 0.70 & 19 & 1 & 376 & 45 & 74 & 12 & 1.54 & 0.46 \\
\hline $\begin{array}{l}\text { A8. Staff who are new to this pharmacy receive } \\
\text { adequate orientation }\end{array}$ & 309 & 48 & 144 & 26 & 0.33 & 0.57 & 17 & 3 & 360 & 61 & 76 & 10 & 0.50 & 0.78 \\
\hline $\begin{array}{l}\text { B1. Staff ideas and suggestions are valued in this } \\
\text { pharmacy }\end{array}$ & 220 & 137 & 101 & 69 & 0.24 & 0.63 & 16 & 4 & 253 & 168 & 52 & 34 & 3.18 & 0.20 \\
\hline $\begin{array}{l}\text { B5. Staff feel comfortable asking questions when they } \\
\text { are unsure about something }\end{array}$ & 255 & 102 & 110 & 60 & 2.45 & 0.12 & 17 & 3 & 289 & 132 & 59 & 27 & 2.42 & 0.30 \\
\hline $\begin{array}{l}\text { B10. It is easy for staff to speak up to their supervisor/ } \\
\text { manager about patient safety concerns in this } \\
\text { pharmacy }\end{array}$ & 193 & 164 & 92 & 78 & 0.000 & 0.99 & 9 & 11 & 232 & 189 & 44 & 42 & 1.14 & 0.57 \\
\hline $\begin{array}{l}\text { B2. We encourage patients to talk to pharmacists about } \\
\text { their medications }\end{array}$ & 192 & 165 & 87 & 83 & 0.31 & 0.58 & 14 & 6 & 217 & 204 & 48 & 38 & 2.96 & 0.23 \\
\hline $\begin{array}{l}\text { B7. Our pharmacists spend enough time talking to } \\
\text { patients about how to use their medications }\end{array}$ & 274 & 83 & 137 & 33 & 0.99 & 0.32 & 13 & 7 & 231 & 208 & 46 & 40 & 1.73 & 0.42 \\
\hline $\begin{array}{l}\text { B11. Our pharmacists tell patients important information } \\
\text { about their new prescriptions }\end{array}$ & 214 & 143 & 94 & 76 & 1.03 & 0.31 & 12 & 8 & 247 & 174 & 49 & 37 & 0.11 & 0.95 \\
\hline B3. Staff take adequate breaks during their shifts & 187 & 170 & 121 & 49 & 16.75 & 0.000 & 18 & 2 & 245 & 176 & 45 & 41 & 9.54 & 0.01 \\
\hline $\begin{array}{l}\text { B9. We feel rushed when processing prescriptions } \\
\text { (negatively worded) }\end{array}$ & 110 & 247 & 87 & 83 & 20.40 & 0.000 & 8 & 12 & 153 & 268 & 36 & 50 & 0.99 & 0.61 \\
\hline B12. We have enough staff to handle the workload & 212 & 145 & 202 & 68 & 0.02 & 0.89 & 15 & 5 & 251 & 170 & 48 & 38 & 2.45 & 0.29 \\
\hline $\begin{array}{l}\text { B16. Interruptions/distractions in this pharmacy (from } \\
\text { phone calls, faxes, customers, etc) make it difficult } \\
\text { for staff to work accurately (negatively worded) }\end{array}$ & 116 & 241 & 71 & 99 & 4.32 & 0.04 & 6 & 14 & 147 & 274 & 34 & 52 & 0.94 & 0.63 \\
\hline $\begin{array}{l}\text { B4. We have clear expectations about exchanging } \\
\text { important prescription information across shifts }\end{array}$ & 171 & 186 & 101 & 69 & 6.11 & 0.01 & 17 & 3 & 333 & 88 & 61 & 25 & 3.37 & 0.19 \\
\hline $\begin{array}{l}\text { B6. We have standard procedures for communicating } \\
\text { prescription information across shifts }\end{array}$ & 241 & 116 & 126 & 44 & 2.28 & 0.12 & 16 & 4 & 303 & 118 & 48 & 38 & 9.87 & 0.01 \\
\hline
\end{tabular}


Table 3 Continued

Items

Hospital levels

Third-grade

hospital

NPR

B14. The status of problematic prescriptions is well communicated across shifts

B8. Staff in this pharmacy discuss mistakes staff discuss them

B15. In this pharmacy, we talk about ways to prevent 283 mistakes from happening again

C1. Staff are treated fairly when they make mistakes

C4. This pharmacy helps staff learn from their mistakes rather than punishing them

C7. We look at staff actions and the way we do things to understand why mistakes happen in this pharmacy

C8. Staff feel like their mistakes are held against them (negatively worded)

C2. When a mistake happens, we try to figure out what problems in the work process led to the mistake

C5. When the same mistake keeps happening, we change the way we do things

C10. Mistakes have led to positive changes in this pharmacy

C3. This pharmacy places more emphasis on sales than on patient safety (negatively worded)

C6. This pharmacy is good at preventing mistakes

C9. The way we do things in this pharmacy reflects a strong focus on patient safety

D1. When a mistake reaches the patient and could cause harm but does not, how often is it documented?

D2. When a mistake reaches the patient but has no potential to harm the patient, how often is it documented?

D3. When a mistake that could have harmed the patient is corrected before the medication leaves the pharmacy, how often is it documented?

\begin{tabular}{|c|c|c|c|c|c|c|c|c|c|c|c|c|c|}
\hline$r n$ & Tun & MVII & Nor & & p value & INTI & s & IVT & iven & GTr & IVug & & \\
\hline 257 & 100 & 126 & 44 & 0.26 & 0.61 & 18 & 2 & 307 & 114 & 58 & 28 & 4.22 & 0.12 \\
\hline 180 & 177 & 72 & 98 & 3.00 & 0.08 & 11 & 9 & 201 & 220 & 40 & 46 & 0.47 & 0.79 \\
\hline 208 & 149 & 84 & 86 & 3.65 & 0.06 & 11 & 9 & 233 & 188 & 48 & 38 & 0.00 & 0.99 \\
\hline 283 & 74 & 116 & 54 & 7.63 & 0.006 & 16 & 4 & 319 & 102 & 64 & 22 & 0.28 & 0.87 \\
\hline 287 & 70 & 131 & 39 & 0.78 & 0.38 & 17 & 3 & 330 & 91 & 71 & 15 & 1.17 & 0.56 \\
\hline 222 & 135 & 120 & 50 & 3.57 & 0.06 & 15 & 5 & 275 & 146 & 52 & 34 & 1.67 & 0.43 \\
\hline 268 & 89 & 117 & 53 & 2.28 & 0.13 & 15 & 5 & 313 & 108 & 57 & 29 & 2.40 & 0.30 \\
\hline 118 & 239 & 68 & 102 & 2.43 & 0.12 & 5 & 15 & 152 & 269 & 29 & 57 & 1.14 & 0.57 \\
\hline 323 & 34 & 145 & 25 & 3.11 & 0.08 & 19 & 1 & 371 & 50 & 78 & 8 & 1.28 & 0.53 \\
\hline 291 & 66 & 127 & 43 & 3.25 & 0.07 & 18 & 2 & 335 & 86 & 65 & 21 & 2.14 & 0.34 \\
\hline 298 & 59 & 118 & 52 & 13.70 & 0.000 & 16 & 4 & 337 & 84 & 63 & 23 & 2.00 & 0.37 \\
\hline 274 & 83 & 132 & 38 & 0.05 & 0.82 & 17 & 3 & 323 & 98 & 66 & 20 & 0.75 & 0.69 \\
\hline 276 & 81 & 116 & 54 & 4.98 & 0.03 & 17 & 3 & 315 & 106 & 60 & 26 & 2.19 & 0.34 \\
\hline 306 & 51 & 129 & 41 & 7.73 & 0.005 & 19 & 1 & 351 & 70 & 65 & 21 & 5.25 & 0.07 \\
\hline 200 & 157 & 99 & 71 & 0.23 & 0.63 & 12 & 8 & 243 & 178 & 44 & 42 & 1.34 & 0.51 \\
\hline 207 & 150 & 95 & 75 & 0.21 & 0.65 & 13 & 7 & 246 & 175 & 43 & 43 & 2.58 & 0.28 \\
\hline 209 & 148 & 95 & 75 & 0.33 & 0.56 & 14 & 6 & 244 & 177 & 41 & 45 & 4.57 & 0.10 \\
\hline
\end{tabular}


Table 4 The comparisons of patient safety grade between different positions of hospital pharmacists

\begin{tabular}{|c|c|c|c|c|c|}
\hline Patient safety grade & Senior pharmacist (\%) & Junior pharmacist (\%) & Pharmacy intern (\%) & China (\%) & USA (\%) \\
\hline Excellent & $2^{*}(6.5)$ & $25(80.6)$ & $4(12.9)$ & $84(16)$ & $191(40)$ \\
\hline Very good & 1 (1.2) & 69 (85.2) & $11(13.6)$ & $227(43)$ & $211(44)$ \\
\hline Good & $6(5.6)$ & $80(74.8)$ & 21 (19.6) & $105(20)$ & $53(11)$ \\
\hline Fair & $7(3.1)$ & $184(81.4)$ & $35(15.5)$ & 79 (15) & $24(5)$ \\
\hline Poor & $4(4.9)$ & $63(76.8)$ & $15(18.30$ & $32(6)$ & 0 \\
\hline
\end{tabular}

The correlation coefficient was 0.43 and the correlation was significant at $\mathrm{p}<0.001$.

\section{Reliability and validity}

This study demonstrated that Cronbach's $\alpha$ was 0.89 for the questionnaire and ranged from 0.17 to 0.83 for dimensions. The dimension 'Communication About Mistakes' had the lowest coefficient of 0.17 (table 2). Yet in the USA, Cronbach's $\alpha$ ranged from 0.68 to 0.89 for dimensions of which 'Staffing, Work Pressure and Pace' had the lowest value of 0.68 .

Bartlett's test of the 35 items on patient safety culture demonstrated a sufficient interitem correlation: $\chi^{2}=12037.98, \mathrm{df}=595, \mathrm{p}<0.01$. Furthermore, the KMO measure of sampling adequacy was satisfactory, with a value of 0.935 . Explorative factor analysis was performed using principal component analysis with varimax rotation drawing seven factors. The factors cumulatively explained $59 \%$ of the variance in the survey and the result was acceptable.

Thirty-three participants responded twice to the questionnaire. For the 35 items, an ICC ranged from 0.30 to 0.94 . Twenty-nine items had an ICC above 0.7 , five items had an ICC between 0.5 and 0.7 and one item had an ICC under 0.5 (table 2).

The intercorrelations of the 11 dimensions and correlations between the scale scores were also calculated. No dimension had high correlations above 0.8 with other dimensions. 'Communication Openness' and 'Patient
Counseling' ( $\mathrm{r}=0.74)$ were most correlated, while 'Staffing, Work Pressure and Pace' and 'Overall Perceptions of Patient Safety' $(r=0.01)$ were least correlated. The highest intercorrelation was between 'Communication Openness' and the scale $(\mathrm{r}=0.78)$. The correlations between each dimension and the total scale were significantly different (table 5).

Finally, table 6 presents the factor loading for each item (all loadings $>0.3$ ): factor 1 loading on five dimensions, factor 2 loading on three dimensions ('Physical Space and Environment', 'Teamwork' and 'Staff Training and Skills') and factor 3 loading on 'Overall Perceptions of Patient Safety'.

\section{DISCUSSION}

The study is the first publication of its kind using the PSOPSC to explore patient culture in hospital pharmacy sector. It is, furthermore, the first Chinese study to report data on perspectives of patient culture at different levels of qualification and hospital in a pharmacy setting. The PSOPSC has been introduced by AHRQ for about 1 year which was only conducted as a pilot study in US pharmacies. ${ }^{20}$ We adopted this survey in our research, because consider that this is a very comprehensive patient safety culture survey focused on the pharmacy sector, which is best suitable for examining patient safety climate from a hospital pharmacy perspective. Moreover, the survey will enable the pharmacies to

Table 5 Correlation with the total scale and intercorrelations of the 11 dimensions

\begin{tabular}{|c|c|c|c|c|c|c|c|c|c|c|c|c|}
\hline Dimensions & 1 & 2 & 3 & 4 & 5 & 6 & 7 & 8 & 9 & 10 & 11 & Total \\
\hline 1. Physical Space and Environment & 1.00 & 0.15 & 0.12 & 0.27 & 0.25 & 0.22 & 0.26 & 0.22 & 0.73 & 0.61 & 0.15 & $0.14^{\star}$ \\
\hline 2. Teamwork & & 1.00 & 0.12 & 0.44 & 0.30 & 0.28 & 0.31 & 0.28 & 0.64 & 0.55 & 0.15 & $0.14^{*}$ \\
\hline 3. Staff Training and Skills & & & 1.00 & 0.39 & 0.34 & 0.33 & 0.44 & 0.33 & 0.56 & 0.44 & 0.09 & $0.16^{*}$ \\
\hline 4. Communication Openness & & & & 1.00 & 0.74 & 0.63 & 0.37 & 0.57 & 0.37 & 0.36 & 0.03 & $0.78^{*}$ \\
\hline 5. Patient Counseling & & & & & 1.00 & 0.70 & 0.70 & 0.70 & 0.20 & 0.02 & 0.05 & $0.76^{\star}$ \\
\hline 6. Staffing, Work Pressure and Pace & & & & & & 1.00 & 0.68 & 0.69 & 0.02 & -0.05 & 0.01 & $0.77^{\star}$ \\
\hline $\begin{array}{l}\text { 7. Communication About Prescriptions } \\
\text { Across Shifts }\end{array}$ & & & & & & & 1.00 & 0.68 & 0.20 & 0.05 & 0.07 & $0.75^{\star}$ \\
\hline 8. Communication About Mistakes & & & & & & & & 1.00 & 0.20 & -0.05 & 0.10 & $0.77^{\star}$ \\
\hline 9. Response to Mistakes & & & & & & & & & 1.00 & 0.32 & 0.04 & $0.17^{*}$ \\
\hline $\begin{array}{l}\text { 10. Organizational Learning-Continuous } \\
\text { Improvement }\end{array}$ & & & & & & & & & & 1.00 & 0.12 & $0.18^{\star}$ \\
\hline 11. Overall Perceptions of Patient Safety & & & & & & & & & & & 1.00 & $0.13^{\star}$ \\
\hline
\end{tabular}


Table 6 Factors loading in each item

\begin{tabular}{|c|c|c|c|c|c|c|c|}
\hline Items & 1 & 2 & 3 & 4 & 5 & 6 & 7 \\
\hline A1. This pharmacy is well organised & & 0.78 & & & & & \\
\hline A5. This pharmacy is free of clutter & & 0.55 & & & & & \\
\hline A7. The physical layout of this pharmacy supports good workflow & & 0.72 & & & & & \\
\hline A2. Staff treat each other with respect & & 0.82 & & & & & \\
\hline A4. Staff in this pharmacy clearly understand their roles and responsibilities & & 0.47 & & & & & 0.30 \\
\hline A9. Staff work together as an effective team & & 0.80 & & & & & \\
\hline A3. Technicians in this pharmacy receive the training they need to do their jobs & & 0.41 & & & & & \\
\hline A6. Staff in this pharmacy have the skills they need to do their jobs well & & 0.41 & & & & & \\
\hline A8. Staff who are new to this pharmacy receive adequate orientation & & 0.66 & & & & & \\
\hline B1. Staff ideas and suggestions are valued in this pharmacy & 0.73 & & & & & & \\
\hline $\begin{array}{l}\text { B5. Staff feel comfortable asking questions when they are unsure about } \\
\text { something }\end{array}$ & 0.97 & & & & & & \\
\hline $\begin{array}{l}\text { B10. It is easy for staff to speak up to their supervisor/manager about patient } \\
\text { safety concerns in this pharmacy }\end{array}$ & 0.95 & & & & & & \\
\hline B2. We encourage patients to talk to pharmacists about their medications & 0.96 & & & & & & \\
\hline $\begin{array}{l}\text { B7. Our pharmacists spend enough time talking to patients about how to use } \\
\text { their medications }\end{array}$ & 0.96 & & & & & & \\
\hline $\begin{array}{l}\text { B11. Our pharmacists tell patients important information about their new } \\
\text { prescriptions }\end{array}$ & 0.61 & & & & & & \\
\hline B3. Staff take adequate breaks during their shifts & 0.73 & & & & & & \\
\hline B9. We feel rushed when processing prescriptions (negatively worded) & 0.92 & & & & & & \\
\hline B12. We have enough staff to handle the workload & 0.61 & & & & & & \\
\hline $\begin{array}{l}\text { B16. Interruptions/distractions in this pharmacy (from phone calls, faxes, } \\
\text { customers, etc) make it difficult for staff to work accurately (negatively } \\
\text { worded) }\end{array}$ & 0.94 & & & & & & \\
\hline $\begin{array}{l}\text { B4. We have clear expectations about exchanging important prescription } \\
\text { information across shifts }\end{array}$ & 0.73 & & & & & & \\
\hline $\begin{array}{l}\text { B6. We have standard procedures for communicating prescription information } \\
\text { across shifts }\end{array}$ & 0.72 & & & & & & \\
\hline B14. The status of problematic prescriptions is well communicated across shifts & 0.96 & & & & & & \\
\hline B8. Staff in this pharmacy discuss mistakes & 0.74 & & & & & & \\
\hline B13. When patient safety issues occur in this pharmacy, staff discuss them & 0.60 & & & & & & \\
\hline $\begin{array}{l}\text { B15. In this pharmacy, we talk about ways to prevent mistakes from happening } \\
\text { again }\end{array}$ & 0.53 & & & & & & \\
\hline C1. Staff are treated fairly when they make mistakes & & & & 0.92 & & & \\
\hline $\begin{array}{l}\text { C4. This pharmacy helps staff learn from their mistakes rather than punishing } \\
\text { them }\end{array}$ & & & 0.65 & & & & \\
\hline $\begin{array}{l}\text { C7. We look at staff actions and the way we do things to understand why } \\
\text { mistakes happen in this pharmacy }\end{array}$ & & & 0.68 & & & & \\
\hline C8. Staff feel like their mistakes are held against them (negatively worded) & & & 0.41 & & 0.54 & & \\
\hline $\begin{array}{l}\text { C2. When a mistake happens, we try to figure out what problems in the work } \\
\text { process led to the mistake }\end{array}$ & & & & & -0.75 & & \\
\hline $\begin{array}{l}\text { C5. When the same mistake keeps happening, we change the way we do } \\
\text { things }\end{array}$ & & & 0.69 & & & & \\
\hline C10. Mistakes have led to positive changes in this pharmacy & & & & 0.91 & & & \\
\hline $\begin{array}{l}\text { C3. This pharmacy places more emphasis on sales than on patient safety } \\
\text { (negatively worded) }\end{array}$ & & & -0.71 & & & & \\
\hline C6. This pharmacy is good at preventing mistakes & & 0.39 & 0.71 & & & & \\
\hline $\begin{array}{l}\text { C9. The way we do things in this pharmacy reflects a strong focus on patient } \\
\text { safety }\end{array}$ & & & 0.43 & & & 0.33 & -0.35 \\
\hline
\end{tabular}

assess areas of strength and identify areas for improvement in their patient safety culture as part of their quality improvement activities.

In our study, the response rate was $84 \%$, which was higher than that of the pilot study implemented in the USA $(75 \%) .{ }^{20} \mathrm{~A}$ high response rate on a questionnaire about safety attitudes might be a measure of the staff's attentiveness to these issues. ${ }^{22}$ Overall, the mean positive response rate for the 11 patient safety culture dimensions of the PSOPSC was $71 \%$, slightly higher than that for the other two studies conducted in Taiwan by Chen and $\mathrm{Li}^{23}$ and the mainland of China by Nie et al. ${ }^{4} \mathrm{On}$ 
comparing with these two studies, we found that the three studies have a common feature in that they predominantly used surveys to assess individual attitudes covering areas related to work environment, adherence to guidelines and safety concerns. ${ }^{24}$ The only difference is that Chen and Nie used the Hospital Survey on Patient Safety Culture (HSPSC) for all healthcare workers within an organisational level, while we used PSOPSC for hospital pharmacy workers, which thereby elicits a snapshot of the safety climate in the specific setting. Meanwhile, in some other studies, the pharmacists surveyed were relatively in a small size in their study populations, such as the HSPSC study in Japan by Ito et $a l^{11}$ in which 155 (2.4\%) pharmacists were included, and the HSPSC study in the USA by Sorra and Dyer ${ }^{12}$ in which 1215 (2\%) pharmacists were included.

Our study found that there was substantial variability in the percentage of positive scores across 11 dimensions. The dimension 'Staff Training and Skill' appeared to receive the highest positive response rate $(88 \%)$. An explanation for this might be the fact that the national job training project for pharmacists in China named 'Clinical Pharmacist Pilot Training' for a long time put great effort into providing clinical pharmacy training for pharmacists who are working or will work as clinical pharmacists from different hospitals. ${ }^{25}$ However, another possible reason for the relatively high proportion of positive responses might be that the translation was inadequate, and that a ceiling effect occurred. 10 Simultaneously, the dimension 'Teamwork' received a positive response rate of $84 \%$ in our study, which is similar to that in the studies reported by Belgium, ${ }^{14}$ Turkey, ${ }^{26}$ Sweden, ${ }^{10}$ the USA, ${ }^{27}$ China $^{4}$ and Taiwan ${ }^{23}$ (70\%, $76 \%, 78 \%, 80 \%, 84 \%$ and $94 \%$, respectively). The interpretation of the results within a given setting is that if $\geq 80 \%$ of the respondents report positive assessments on a specific item or set of items, then there is a strong positive consensus in that setting. ${ }^{10}$ A score of less than $60 \%$ is considered to be in the "needs improvement' range. ${ }^{10}$ Hence, $\geq 60 \%$ is a threshold for which the safety climate can be considered acceptable.

This study displayed that in China and the USA, the dimension that received the lowest positive rate was 'Staffing, Work Pressure and Pace' $(50 \%$ and $41 \%$, respectively), indicating that the respondents feel that staff allocation is not adequate to handle the patient safety related workload. ${ }^{4}$ Our results are in accordance with those reported by Hellings $e a^{14}$ and the study conducted in Taiwan and China. ${ }^{23} 28$ Meanwhile, a study by Elisa $\mathrm{E}$ in a Northern California hospital of the USA showed that the most common causes of medication errors were high workload $(25.3 \%)$, fatigue or lack of sleep $(16.5 \%) .^{29}$ Therefore, it is important for the pharmacy to allocate staff and working hours more adequately to reduce the medication errors and improve patient safety. In addition, in our study, another relatively low positive response rate was the dimension 'Patient Counseling' $(57 \%)$, which reflected the problem in
China: poor healthcare worker-patient (including pharmacy staff-patient) communication. A study by Zou and Zhao $^{30}$ in China indicated that $49 \%$ of the medical lawsuits were related to poor healthcare worker-patient communication. A study by Moore $e t a l^{31}$ showed that of 635 complaints that involved a doctor, 49 cases $(15 \%)$ were because of 'Lack of communication'. Lack of 'communication openness' was identified as a major safety culture problem. In other words, communication openness was seriously jeopardised by the lack of trust between health workers and patients in China as reported by Liu $e t a \hat{l}^{2}$ in a recent study.

The results showed that the positive response numbers of a third-grade hospital regarding patient safety culture was higher than that of a second-grade hospital. The reason for this may be that in China, the third-grade hospital always manages severe clinical cases, so the pharmacies of a third-grade hospital have a higher potential for life-threatening medical errors. As most risky medical interventions take place in these hospitals, the staff have to get better training to deal with safety-related issues. ${ }^{26}$ Simultaneously, our study found that the positive response rate of pharmacists with high qualification (senior pharmacists) was higher than those with a low qualification level (junior pharmacists) on the dimension 'Staffing, Work Pressure and Pace'. Senior healthcare workers have been found to bring about experience, ${ }^{22}$ as they know the pitfalls of the pharmacy work and can avoid them masterly which might reduce the risk for error making, so senior pharmacists might work more effectively and had a positive attitude to their work pressure. This was also elucidated in the study by Sorlie $e t a l^{33}$ who found that the more experience physicians gained, the more confident they would feel. So we can infer that experiential proficiency is a pre-requisite to this higher positive response.

The pharmacy is an important link between the patient and medication, so developing a culture of safety has become one of the pillars of the pharmacy. According to the report of the China Food and Drug Administration (CFDA), a total of 852799 drug adverse events happened in China in 2011. ${ }^{7}$ The Chinese Hospital Association (CHA) estimated that adverse events affect 1.6-7.6 million hospitalisations annually in Chinese hospitals. ${ }^{34} \mathrm{~A}$ study by Li $e t a l^{35}$ showed that 1165 medication errors were reported by 22 hospitals in Beijing in 2012 and another study by Li $e$ e $a l^{36}$ in China indicated that $32(26.30 \%)$ dispensing errors were applied to the pharmacists and $5(4.03 \%)$ dispensing errors were related to the environment of the pharmacy. The adaptation of this instrument to the Chinese pharmacy context not only is an important milestone for safety research in pharmacies but also provides the pharmacies with an instrument that generates diagnostic and actionable information for pharmacies and leaders to use in guiding improvement efforts. ${ }^{37}$ The findings of the study illustrated that pharmacies and healthcare organisations in China should have imperatives to 
develop strategies to improve pharmacy service quality and ensure patient safety. These strategies include: strengthening patient safety training for pharmacy staff, reasonable allocation of staff and workload, creating an environment conducive to reporting errors by focusing on the process or system failure instead of the individual who committed the error. ${ }^{38}$ What is more, we should raise awareness of the importance of patient engagement in improving medication safety because a global concerted effort is needed to address medication safety and it needs the involvement of all healthcare stakeholders, including patients. In addition, building trust between providers and patients and between managers and health workers is essential for empowering health workers to address patient safety issues. ${ }^{32}$

Finally, although patient safety activity is getting recognised in China, there are still many challenges and difficulties in implementing this activity. For example, our initial design was to include 1000 pharmacy staff from 50 hospitals across China. However, the hospitals where we investigated were very sensitive and they did not like to 'open' their 'data' or they were concerned whether this would influence the reputation of hospitals. Therefore, each time, we needed to negotiate and explain our purpose to get the approval from the relative responsible persons, which was a time-consuming experience and making our survey last for about 6 months and which was also the reason why our sample size was not big enough. We wish this would be changed with the implementation of patient safety activity in the country.

\section{Reliability and validity}

Using the explorative factor analysis, seven factors were drawn. The factors cumulatively explained $59 \%$ of the variance in the survey and the result was acceptable. Using Cronbach's $\alpha$, all subscales had acceptable levels of reliability, which varied from 0.84 for 'Communication About Prescriptions Across Shifts' to 0.44 for 'Teamwork', with the exception of the dimension 'Communication About Mistakes' which had the lowest value of 0.17 . The results were less satisfactory as compared with AHRQ data. ${ }^{20}$ The dimension 'Communication About Mistakes' received the lowest Cronbach's $\alpha$ among the 11 dimensions; three reasons could account for this. First, a possible explanation was the translation; scale should not be translated and applied in another setting of a different cultural context directly. ${ }^{4}$ Second, the factor structure of the PSOPSC model for these items might not fit the data well. ${ }^{23}$ Third, the sample size of the data might not be large enough to achieve consistency. ${ }^{23}$ However, the low reliability also suggested the instability of the aspects measured by the questionnaire, which are based on professionals' perceptions of safety (themselves linked to safety circumstances at a given time, and inherently unstable and subject to change). If culture does not change so rapidly, perceptions do. ${ }^{21}$ Finally, unlike other similar studies published anywhere focused on tool evaluation or developing the survey tool, the primary objective of our study was "to explore the attitudes and perceptions of patient safety culture for pharmacy workers in China by using a Pharmacy Survey on Patient Safety Culture." Hence, we did not conduct a confirmatory factor analysis to test hypotheses about a particular factor structure which might be a weak point in this study. However, we will take this into consideration with a larger sample size in our future study.

\section{CONCLUSION}

The results demonstrated that among the pharmacy staff surveyed in China, there was a positive attitude towards patient safety culture in their organisations. The Chinese translation of the PSOPSC questionnaire (V.2012) used in our study was acceptable.

\section{Author affiliations}

${ }^{1}$ Chinese Evidence-Based Medicine, West China Hospital, Sichuan University, Chengdu, People's Republic of China

${ }^{2}$ Department of Pharmacy, West China Second University Hospital, Chengdu, People's Republic of China

${ }^{3}$ Department of Fetal Medicine, Sichuan Provincial Hospital for Women and Children, Chengdu, People's Republic of China

${ }^{4}$ Department of Pharmacy, The Sixth Chengdu Hospital, Chengdu, People's Republic of China

${ }^{5}$ Department of Pharmacy, West China Hospital, Sichuan University, Chengdu, People's Republic of China.

Acknowledgements The authors would like to thank all the respondents who took part in this study. They also thank Professor Kang Deying for his statistical support and Miss Kathren Sieminski for her help with English revision.

Contributors MMZ conceptualised and designed the study. PLJ and LHZ performed and interpreted the data analysis. MMZ and PLJ drafted and revised the manuscript critically for intellectual content. The rest of the authors collected the data and checked the data input. All authors read and approved the final manuscript.

Funding This project was supported by the National Natural Science foundation N0.70973083.

\section{Competing interests None.}

Ethics approval This was a non-interventional survey. We were informed that it was not a mandatory requirement for ethics approval by the hospital ethics committee. However, responding to the questionnaire was voluntary and all answers were de-identified to maintain confidentiality.

Provenance and peer review Not commissioned; externally peer reviewed.

Data sharing statement No additional data are available.

Open Access This is an Open Access article distributed in accordance with the Creative Commons Attribution Non Commercial (CC BY-NC 3.0) license, which permits others to distribute, remix, adapt, build upon this work noncommercially, and license their derivative works on different terms, provided the original work is properly cited and the use is non-commercial. See: http:// creativecommons.org/licenses/by-nc/3.0/

\section{REFERENCES}

1. Bond CA, Raehl CL, Franke T. Clinical pharmacy services, hospital pharmacy staffing, and medication errors in United States hospitals. Pharmacotherapy 2002;22:134-47.

2. Kaushal R, Shojania KG, Bates DW. Effects of computreized physician order entry and clinical decision support systems on medication safety. Arch Intern Med 2003;163:1409-16. 
3. Kelly WN. Potential risks and prevention, part 4: reports of significant adverse drug events. Am J Health Syst Pharm 2001;58:1406-12.

4. Nie $\mathrm{YL}, \mathrm{Mao} X Y, \mathrm{Cui} H$, et al. Hospital survey on patient safety culture in China. BMC Health Serv Res 2013;13:228.

5. Benjamin DM. Reducing medication errors and increasing patient safety: case studies in clinical pharmacology. J Clin Pharmacol 2003;43:768-83.

6. Patel I, Balkrishnan R. Medication error management around the globe: an overview. Indian J Pharm Sci 2010;72:539-45.

7. The national annual report of adverse drug reaction monitoring in 2011. http://www.sda.gov.cn/WS01/CL0078/72193.html (accessed May 2012).

8. Hartigan-Go K. Developing a pharmacovigilance system in the Philippines, a country of diverse culture and strong traditional medicine background. Toxicology 2002;181-182:103-7.

9. Westat R, Martha F, Joann S. Pharmacy survey on patient safety culture: user's guide. Agency for Healthcare Research and Quality, 2012. (Prepared by Rockville, MD 20850 Contract No. HHSA290200710024C). AHRQ Publication No. 12(13)-0085. http:// www.ahrq.gov/professionals/quality-patient-safety/ patientsafetyculture/pharmacy/index.html

10. Norden-Hägg A, Sexton J, Kälvemark-Sporrong S, et al. Assessing safety culture in pharmacies: the psychometric validation of the Safety Attitudes Questionnaire (SAQ) in a national sample of community pharmacies in Sweden. BMC Pharmacol Toxicol 2010;10:8.

11. Ito S, Seto K, Kigawa M, et al. Development and applicability of Hospital Survey on Patient Safety Culture (HSOPS) in Japan. BMC Health Serv Res 2011;11:28.

12. Sorra JS, Dyer N. Multilevel psychometric properties of the AHRQ hospital survey on patient safety culture. BMC Health Serv Res 2010;10:199.

13. Singer SJ, Gaba DM, Geppert JJ, et al. The culture of safety: results of an organization-wide survey in 15 California hospitals. Qual Saf Health Care 2003;2:112-18.

14. Hellings J, Schrooten W, Klazinga N, et al. Challenging patient safety culture: survey results. Int J Health Care Qual Assur 2007;20:620-32.

15. Nieva VF, Sorra J. Safety culture assessment: a tool for improving patient safety in healthcare organizations. Qual Saf Health Care 2003;12:ii17-23.

16. Kanse $L$, van der Schaaf TW, Vrijland ND, et al. Error recovery in a hospital pharmacy. Ergonomics 2006;49:503-16.

17. Phipps DL, De Bie J, Herborg $\mathrm{H}$, et al. Evaluation of the Pharmacy Safety Climate Questionnaire in European community pharmacies. Int J Qual Health Care 2012;24:16-22.

18. Ashcroft DM, Morecroft C, Parker D, et al. Safety culture assessment in community pharmacy: development, face validity, and feasibility of the Manchester Patient Safety Assessment Framework. Qual Saf Health Care 2005;14:417-21.

19. Ashcroft DM, Parker D. Development of the Pharmacy Safety Climate Questionnaire: a principal components analysis. Qual Saf Health Care 2009;18:28-31.

20. Westat. 2012 Preliminary comparative results: pharmacy survey on patient safety culture. Department of Health and Human Services, 2012. (Prepared by Westat, Rockville Contract No. HHSA
290200710037). AHRQ Publication No. 12-0085-1-EF: U.S. http://www.ahrq.gov/professionals/quality-patient-safety/ patientsafetyculture/pharmacy/index.html

21. Occelli $P$, Quenon JL, Kret M, et al. Validation of the French version of the Hospital Survey on Patient Safety Culture questionnaire. Int $J$ Qual Health Care 2013;25:459-68.

22. Norden-Hagg A, Kalvemark-Sporrong S, Lindblad AK. Exploring the relationship between safety culture and reported dispensing errors in a large sample of Swedish community pharmacies. BMC Pharmacol Toxicol 2012;13:4

23. Chen IC, Li H-H. Measuring patient safety culture in Taiwan using the Hospital Survey on Patient Safety Culture (HSOPSC). BMC Health Serv Res 2010;10:152.

24. Colla JB, Bracken AC, Kinney LM, et al. Measuring patient safety climate: a review of surveys. Qual Saf Health Care 2005;14: 364-6.

25. Bao N-J, Shao $\mathrm{H}$, Nie $X-Y$, et al. Analysis of the status of clinical pharmacist pilot training in Chinese hospitals. Chin Pharm Sci 2011;20:410-14.

26. Bodur S, Filiz E. A survey on patient safety culture in primary healthcare services in Turkey. Int J Qual Health Care 2009;21:348-55.

27. Joann S, Theresa F, Naomid D, et al. 2012 User comparative database report: hospital survey on patient safety culture. Agency for Healthcare Research and Quality, 2012. (Prepared by Westat, Rockville, MD under Contract No. HHSA 290200710024C). http:// www.ahrq.gov/professionals/quality-patient-safety/ patientsafetyculture/hospital/2012/index.htm

28. Zhu J, Li L, Li Y, et al. What constitutes patient safety culture in Chinese hospitals. Int J Qual Health Care 2012;24:250-7.

29. Nguyen EE, Connolly PM, Wong V. Medication safety initiative in reducing medication errors. J Nurs Care Qual 2010;25:224-30.

30. Zou B, Zhao S. The application analysis of communication skill in reconstructing the harmonious doctor-patient reationship. J Med Theory Pract 2013;26:1676-8.

31. Moore $\mathrm{P}$, Vargas A, Núñez $\mathrm{S}$, et al. A study of hospital complaints and the role of the doctor-patient communication. Rev Med Chil 2011;139:880-5.

32. Liu C, Liu W, Wang Y, et al. Patient safety culture in China: a case study in an outpatient setting in Beijing. BMJ Qual Saf 2014;23:556-64.

33. Sorlie V, Lindseth A, Uden G, et al. Women physicians' narratives about being in ethically difficult care situations in paediatrics. Nurs Ethics 2000;7:47-62.

34. Cao RG. Medical quality and patient safety in China. Chin Hosp 2007;11:1-4.

35. Li XL, Yan SY, Wang YQ, et al. Analysis of 1165 medication errors among 22 hoapitals in Beijing. Adverse Drug React J 2013;2:64-8.

36. Li XY, Lai BL, Li SL, et al. Error analysis of hospital outpatient pharmacy from 2010 to 2011. Pharm Today 2012;8:496-7.

37. Sexton JB, Paine LA, Manfuso J, et al. A culture check-up for safety in "my patient care area". Jt Comm J Qual Patient Saf 2007;33:699-703

38. Hughes RG, Clancy CM. Working conditions that support patient safety. J Nurs Care Qual 2005;20:289-92. 